\title{
EXAMINATION OF THE SYSTEM OF CONTINUOUS DIAGNOSIS AND FORECASTING OF MECHANICAL CONDITION OF TRACTORS AND OTHER FARM MACHINERY
}

\author{
Ildar Gabitov ${ }^{1 *}$, Samat Insafuddinov ${ }^{1}$, Yurij Ivanov ${ }^{2}$, Nail Yunusbaev ${ }^{1}$, Farid Abdrazakov ${ }^{1}$, Timur Farhutdinov ${ }^{1}$ \\ ${ }^{1}$ Bashkir State Agrarian University, Russian Federation \\ ${ }^{2}$ Federal state budgetary scientific institution all-Russian research Institute of animal husbandry \\ mechanization, Russian Federation
}

The paper presents an experimental system of continuous diagnosis and forecasting of the technical condition of tractors and other farm machinery. The system has both advantages and disadvantages. The experiments proved that the imprecisions of the existing Russian domestic sensors and actuating devices are several times higher than the permissible errors of engine parameters and its process conditions, which were determined based on the analysis of the engine adjusting characteristics. The system we offer allows to expand significantly the possibilities of the use of the agricultural aggregates, machines and implements and to reduce the down and repair time. The existing microprocessor side system significantly simplifies the synthesis of the proposed system and expands the technological capabilities. It allows to make automatic diagnosis of the technical condition of the machine-tractor aggregate (MTA) and makes it possible to obtain information on the need for motor maintenance (MM) if necessary. The option of voice information makes the operator work easier and thereby increases the efficiency of MTA field work.

Key words: diagnostic, prediction, indication, controller, telematics.

\section{INTRODUCTION}

Constant modernization and upgrade of the technological means are a must for efficient development of the agricultural production [1].The analysis of scientific and technical publications showed [1-19] that mechatronic (telematic) side systems are becoming the basis of technical progress in agricultural engineering. At the same time, diagnostics of their technical condition is a standard procedure for all microprocessor systems. Thus, the level of technological infrastructure of agricultural production is determined by the presence of mechatronic control systems and performance control of tractors and other agricultural machinery. Mechatronic systems include: By dividing mechatronic systems into the above mentioned components, we can speak about a threepronged continuous functionally-complete system. Its power unit consists of rather simple mechanical assemblies, which act as performers in this system. The informative part is embedded into the executable software and recorded in microprocessors making a whole of the entire MTA system [5].

The functions of the operator (tractor-driver) in this system are limited. These functions include starting the engine, controlling the operation of all systems, driving and stopping the unit, interfering with the operation of the automatic control system (ACS) in extreme situations, and stopping the engine. In some cases, the operator controls directly the MTA operating mechanisms by signals from sensors or control elements on the information display. However, only some systems can perform self-control. Thus, for example, Motronic system by Bosch can self-diagnose ignition and fuel injection [4]. The integrated system of "Hardware-in-the-Loop" type for the agricultural tractors [15] allows to determine the faults and display the error codes during scanning. Unlike tractors, almost all modern cars have a built-in digital Controller Area Network (CAN) interface for data transmission [4]. MTA differ from cars in the principle of their operation and diagnosis.

Having analyzed the results of works in this area [4-19], we have systematized the requirements for diagnostic systems:

First, the system shall ensure the warning of the operator and the owner of the management object about the system faults or the diagnostic system itself using the indicators, displays and audio warning unit as well as book an appointment at the service center.

Second, the system shall ensure the access to the technical information and its storage, in particular, warning information in the control panel and data on certain faults. Herewith, the data on the engine's operating conditions will be saved during the fault's detection. The type and completeness of the information are subject to standards SAE J1978, SAE J1979 and SAE J2205. The data, stored in the memory of the self-diagnostic system is transferred to the failure-detecting stand, equipped with display through GSM channel. Afterwards, the personnel shall contact via the Internet the central server, detecting the fault and suggesting the algorithm of its remedy in a form of the step-by-step instructions. Communication protocols are specified in standards ISO 9141-3 and ISO 14230-4 [4]. 
Third, the tractors and agricultural machines modern designs shall be equipped with the autonomous trouble-shooting systems. Such systems allow to significantly expand the possibilities of the various agricultural aggregates, machines and implements use. For example, continuous monitoring of the technical condition of the MTA ensures timely maintenance, which increases the level of operational reliability and machine efficiency. The micro-processing control can widen significantly the technological possibilities, and the side microprocessor system ensures the automated diagnostic of the MTA technical state. It provides the information on the required technical maintenance (TM), if necessary. The audio warning option facilitates the operator's work, thus improving the operation of the MTA field works.

Therefore, the work is aimed at the study of the system and interrelations during the implementation of the remote continuous diagnostic and work prediction of the autotractor and agricultural machinery systems.

The practical use of the study results optimizes the MTA diagnostic process and improves operating reliability of its equipment.

\section{MATERIALS AND METHODS}

The subject of the study is the remote continuous diagnostic and work prediction system, which ensures the technical information exchange, coming from the available MTA sensors in the process of the movement with the changing pulling load. As additional sensors, it is recommended to use the ESM-27E oil quality sensor and the residual brake lining thickness sensor of type Z-TP1(Figure 1, Table 1).The information comes from the system to the central diagnostic server, which deter- mines the fault and suggests the variants of their remedy in a form of a step-by-step instructions for the management subject, individually for the personnel of the workshop and in software in a form of prediction of the faults and required repair operations. The object study was performed under the field operating conditions using the simulation mode of the complicated technological processes, using the queuing theory and methods of observation and experiment.

The mathematic processing of the experimental data was performed using the software with three approaches: using the dispersion analysis, ensuring the significance of differences between the groups by each variable; using the cluster analysis, related to the division into homogenous groups within the whole selection; using Data Mining analysis, which diagnoses logical regularities.

The reliability of the results and conclusions of the research was provided by sampling, the use of mathematical and statistical methods, and a meaningful analysis of the revealed factual material.

Scientific novelty is a possibility of remote continuous diagnostic, faults prediction and repair planning of domestic automotive and agricultural equipment in real time.

Results of the experimental studies and their analysis. Experimental MTA was equipped with tractor Belarus 1523 with 155 h.f. engine and shallow plough LDG-5 with disc harrow BDN-3 (Figure 2).

Let us consider the operation of this aggregate as the dynamic system under the environmental effect $\mathrm{Fi}(\mathrm{t})$ (Figure 3).

In this case the management subject - a tractor operator, accepts only the output signals $x_{i}(t)$ from the tractor and implements reading instruments (engine crankshaft

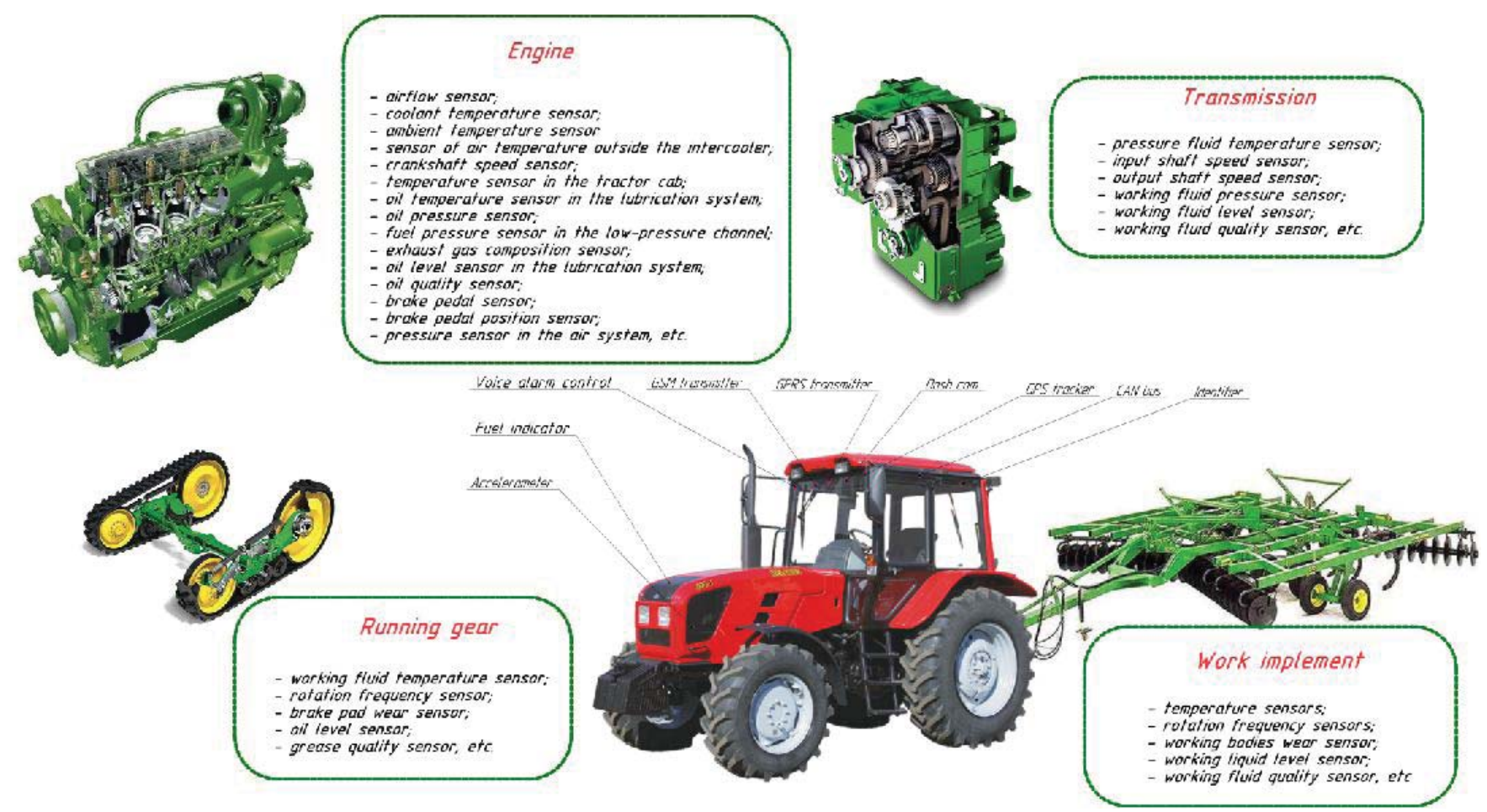

Figure 1: Diagram of the distribution of sensors in the power units of the machine 
Table 1: Sensorsof the MTA operation

\begin{tabular}{|c|c|c|}
\hline Used sensors & & Diagnostic parameters \\
\hline \multicolumn{3}{|c|}{ of the tractor engine and transmission } \\
\hline \multirow{5}{*}{$\begin{array}{ll}\text { - } & \text { fuel consumption DFM } \\
\text { - } & \text { Contoil } 8 \mathrm{D} / \mathrm{S} ; \\
\text { inductive crankshaft } \\
\text { PRAVT } 233847^{*} \text { positions; } \\
\text { - } \quad \text { fuel control lever 6PV } 010 \\
\text { 946-001 positions; } \\
\text { - } & \text { vibrations BD06A; } \\
\text { - } & \text { oils quality ECM-27 E }\end{array}$} & $g_{e}, N_{e}, M_{e}$ & $\begin{array}{l}\text { Respectively specific engine fuel consumption, engine } \\
\text { power and torque }\end{array}$ \\
\hline & $\omega$ & Engine speed \\
\hline & $K_{m}$ & Engine lugdown and recovery by torque \\
\hline & $\varepsilon_{m}$ & Engine load ratio \\
\hline & $\begin{array}{l}\eta_{e} \\
\eta_{t r^{\prime}}\end{array}$ & Effective engine efficiency, transmission efficiency \\
\hline \multicolumn{3}{|c|}{ of the whole MTA } \\
\hline \multirow{8}{*}{$\begin{array}{l}\text { - } \\
\text { speedMTZ-80, } \\
\text { 82AP70.3843-01; } \\
\text { - } \quad \text { forcesDU-03-60 TУРБ*; } \\
\text { - } \quad \text { endue M425; } \\
\text { end-effector positions } \\
\text { Z-TP1-P06; } \\
\text { - fuel consumption DFM } \\
\text { Contoil } 6 \text { D/S. }\end{array}$} & $v, n_{w}$ & Effective velocity and driven wheels rotation frequency \\
\hline & $P_{t}$ & Pulling force \\
\hline & $M_{v}$ & PTO shaft torque \\
\hline & $H, B_{p}$ & Operating depth and aggregate's operating width \\
\hline & $\delta, P_{a} l ., \lambda$ & $\begin{array}{l}\text { Respectively slipping and additional loading for } \\
\text { trailing weight increase and tractor trailing weight } \\
\text { percentage, used for pulling force generation }\end{array}$ \\
\hline & $r_{d}, p_{w}$ & Driven wheel dynamic roller radius and tire air pressure \\
\hline & $f$ & Tractor rolling resistance coefficient \\
\hline & $g_{e^{\prime}} \eta f$ & $\begin{array}{l}\text { Specific traction fuel consumption, traction efficiency } \\
\text { factor }\end{array}$ \\
\hline \multicolumn{3}{|c|}{ of separate aggregate assemblies } \\
\hline \multirow{7}{*}{$\begin{array}{ll} & \text { pressure, type MD } \\
& 50 \ldots 100, \text { TPMS Hid1100*; } \\
\text { - } & \text { temperature, type TP*; } \\
\text { - } & \text { general purpose lambda } \\
& \text { probe Is001-2*; } \\
\text { - } & \text { positions Z-RFC-P01; } \\
\text { - } & \text { indicating I-TYPE 2018; } \\
\text { - } & \text { pressure F-TYPE 2018, M } \\
\text { D100. }\end{array}$} & $p_{a}, p_{o}, p_{c}$ & $\begin{array}{l}\text { Respectively pressure in the hydraulic system (oil), } \\
\text { lubricating system (oil), cooling (antifreeze solution), } \\
\text { tires (air). }\end{array}$ \\
\hline & $t_{o}, t_{c}, t_{a}$ & $\begin{array}{l}\text { Respectively temperature in the lubricating, cooling } \\
\text { and actuating fluid systems }\end{array}$ \\
\hline & $h_{f}$ & Actuating fluids level \\
\hline & 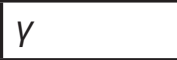 & Emissions oxygen content \\
\hline & $\delta_{b}$ & Brake lining wear \\
\hline & $p_{z}$ & Engine cylinder pressure \\
\hline & $p_{i}$ & Injection pressure of engine fuel nozzles \\
\hline
\end{tabular}

*installed on the aggregate by the manufacturer.

speed, travel velocity, cooling system fluid temperature, oils pressure, operating depth etc.), providing feedback and affecting the controls $c_{i}(t)$. At the same time, he constantly controls the technological process (during dehulling, mainly absence of the fail places and laps), ensuring the required specified parameters $z_{i}(t)$ and aggregate safety during operation.

During the experiments on functions a tractor operator had to make decisions on the control activity such as direction change, fuel feeding or gearshift, to solve the off-schedule tasks, taking into account speed rate maintenance of the specified technology $(12 \mathrm{~km} / \mathrm{h})$ as well as its deviations and external factors. The shallow plough design presupposed the lead angle changes within $0-30^{\circ}$ using the hydraulic system.

As a result, it appeared that a human could not always be able to process completely the interrelated information flow and make the most adequate solution during the operation because of his limited physiological capabilities. The frequency of deviations from the width of the grasp per shift with a fixed impinging angle was up to 3 times per hour by the end of the working shift. During the tractor operator's additional load, when he had to record the engine technical indicators once an hour, this indicator increased up to 5 . 


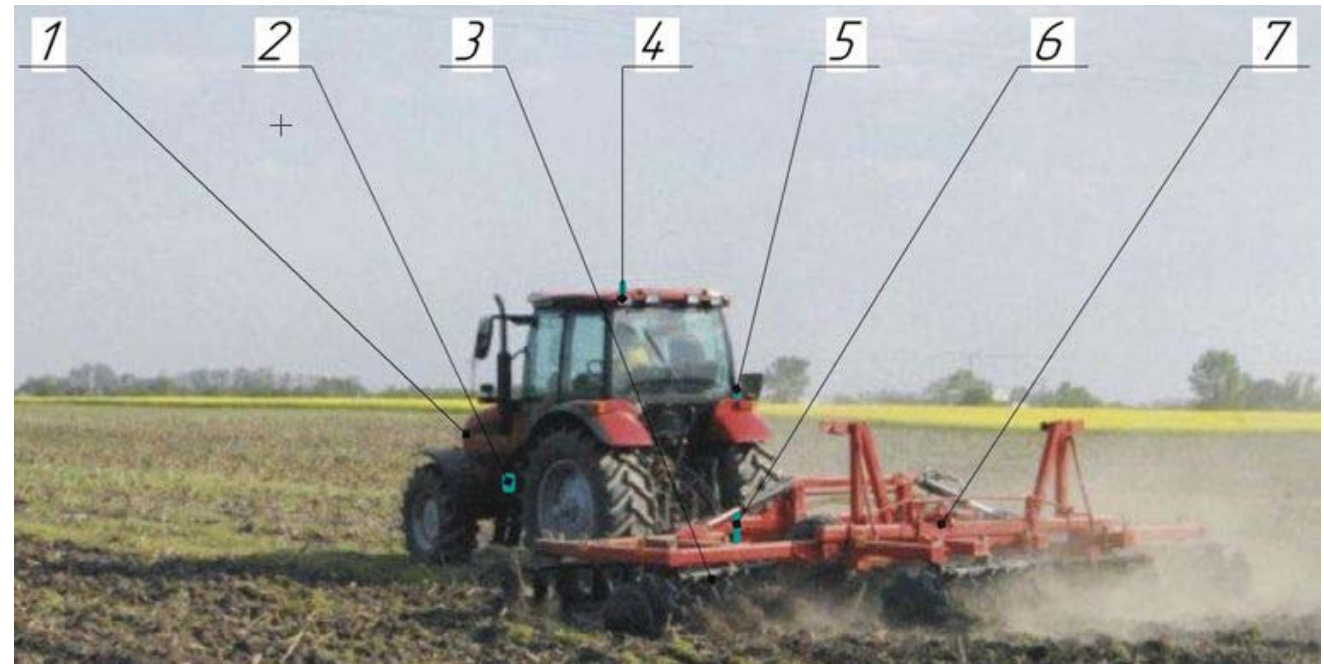

Figure 2: Basic experimental plant;

1 - tractor Belarus 1523; 2 - electronic control unit; 3 - disc shallow plough; 4 - satellite antenna; 5 - GPS antenna; 6 - actuating device depth gauge; 7 - disc harrow

Control object

Control object

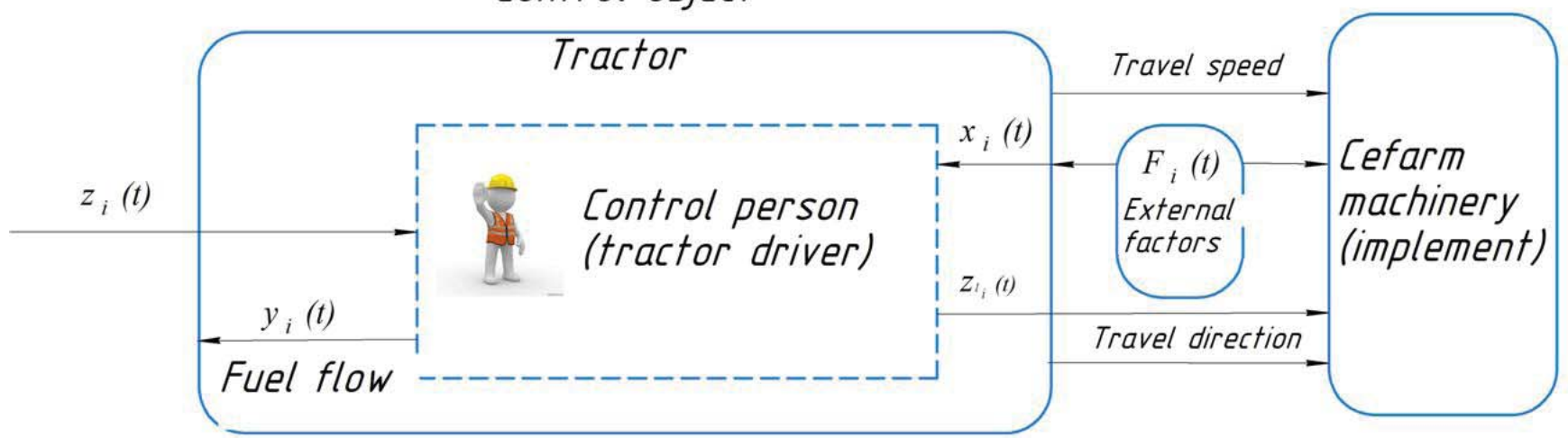

Figure 3: Existing control scheme of the machine-tractor aggregate operation

In order to relieve the tractor operator during the tests the tractor was equipped with a number of the non-standard sensors (they are shown in Table 1 without * ${ }^{*}$ sign). Moreover, scheme 3 was used to assemble special system. The suggested control, side diagnostic and fault prediction system (CDS) provided the feedback $y_{i}(t)$. This CDS variant accepted the output signals $y_{i}(t)$, transformed them into a digital form, processed according to the set algorithm [12] under the specified parameters $z_{i}(t)$, compared the output signals with the required for the drawing machine and implements and sent the control signal to the actuating mechanisms $z_{i 1}(t)$, triggering the tractor's operating mechanisms, determined the error and, if necessary, it also informed the tractor operator, service or agricultural departments on the parameters to be changed, on the planned spares replacement or adjustment parameters.

The principal elements of the suggested system [2] were the electronic control unit (as in Figure 5: microprocessor assembly with communications terminal $A$, satellite antenna $B$, wire harness $C$ and GPS antenna $D$ to transfer the data to the server using the wireless network) and the sensors, connected to the transmission data of attire, running gear and assemblies (Figure 6), allowing to perform independently the MTA technical state continuous control.

The microprocessor assembly is made based on microprocessor SAB100C917A by SIEMENS; it has 25 Kbyte core-memory (RAM) and 2018 Kbyte read-only memory (ROM) 2018.

The system microprocessor assembly is based on the diagnostic and prediction program, used to determine the belongings of the output control and technological parameters-adapters $x_{i}$ measured values to the set required intervals, limited by minimum $x_{i \text { min }}$ and maximum $\mathrm{x}_{i \max }$ values

$x i \rightarrow[y i \min$, yi $\max ], i=1, \ldots, n$

If value $x_{i}$ was within the specified accepted interval, the system aggregate operation (assembly, spare part) is considered possible and stable. Otherwise, the CDBS sends a control signal to switch the system into a stable condition and records the error if the respond is unsatisfactory. After that the error is analyzed in order to choose further actions.

Thus, we showed function (1) as an interval pattern 


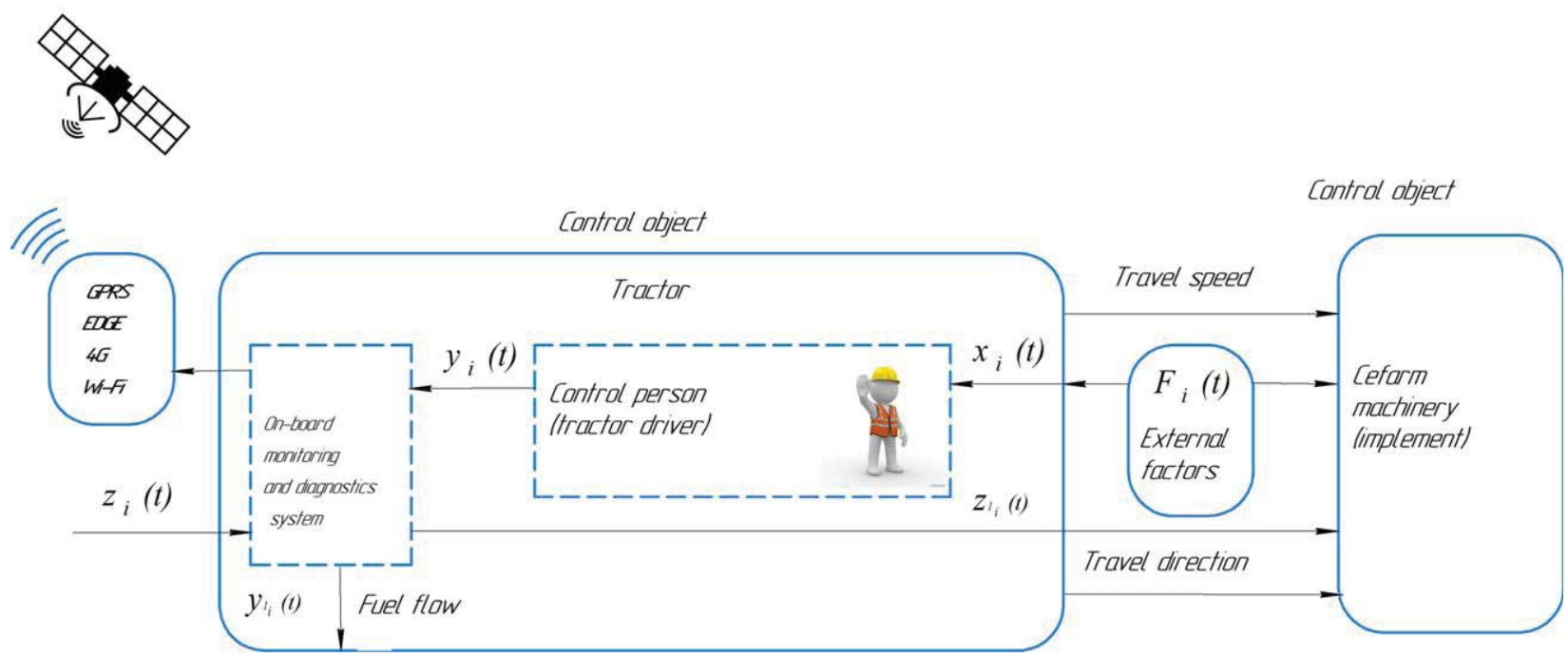

Figure 4: Modified control scheme of the machine-tractor aggregate operation

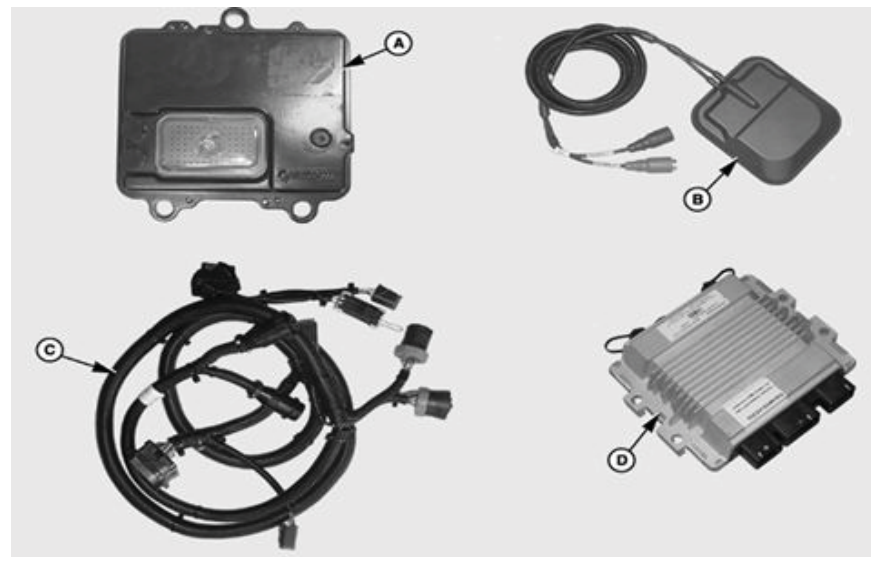

Figure 5: Components of CDBS (check-out, diagnosis and breakdown forecast system): A - microprocessor assembly with communications terminal, $B$ - satellite antenna, $C$ - wire harness and D - GPS antenna

$x_{i} \rightarrow\left[(1-\Delta x) x_{i}^{m p},(1+\Delta x) y_{l}^{m p}\right]$

Where $\Delta \mathrm{x}$ - acceptable deviation of $x_{\mathrm{i}}$ parameter from optimal value $x_{i}^{\text {Tp }}$.

We split control operation parameters (markers) $x_{i}$ into energetic and operating for the sake of convenience (Table 1). The first group includes the values, which depend on the fuel injected to the cylinder, i.e. effective power $N_{e}$ and specific effective fuel consumption $g_{e}$ torque $M_{e}$, adjustability factor $k_{m}$ and engine crankshaft rotation frequency $\omega_{H}$. These parameters were adjusted on the stands before the technological operation. The final operating weight $m_{\ni}$ of the tractor with ballast was $6260 \mathrm{~kg}$. This value did not change during the operation.

The operating parameters characterizing technical and economic aggregate indicators during the working stroke were measured and controlled. Load ratio by torque $\varepsilon_{M}=M_{K} / M_{H}$ was used as the resulting indicator, which characterizes the loading mode [11].

The forecast for the engine working parameters was made based on the separate assemblies operating mark- ers, and the input indicators - under random variables, as they comply with a normal probability law. Thus, we considered the tractor and working machine parameters, adjustable during the working stroke and aggregate technical and economic indicators as the random variables.

Let us show the whole data flow within system MTA CDS as a multiple dynamic system being a part of the aggregate (Figure 6).

It was convenient to split the system in four device groups in accordance with the specified structural scheme: engine, transmission, travel system and implement. The experiments proved that the imprecisions of the existing Russian domestic sensors and actuating devices are several times higher than the permissible errors of engine parameters and its process conditions, which were determined based on the analysis of the engine adjusting characteristics.

In order to describe each group functioning for adaptation, we arrange the output parameters-markers dependencies on the input. Thus, the crank shaft rotation frequency $\omega$, which depends on moment of resistance $M_{c}=M_{e}$, will be used as the output parameter-marker at the established energetic tractor parameters $\left(N_{e}=116 \mathrm{kWm}\right)$ and engine characteristic $\left(M_{e}=603 \mathrm{Nm}\right.$, $k_{m}=16,5 \%, n=2100$ ). The below mentioned dependency can be used to describe this equipment group functioning when using the tractor in the traction mode.

$n=f\left(M_{\varepsilon}\right)=f\left(M_{c}, \omega_{M c}, K_{s}\right)$

The state of this group can be assessed using the following sensors parameters $p_{m}, t_{m}, p_{o}, t_{o}, h_{g}, Y$ (See Table 1). Additional electrical oil change sensor ECM-27 E was implemented to control the motor oil quality (Table 1). The active level was programmed before connecting the sensor to the controller. After that, the "alarm zone boundaries" were set so that the input voltage when inactive was in the middle of the alarm zone, and in case of a stub closure or its break - overran it. Input $5 \mathrm{~V}$ voltage is the maximum level $100 \%$. 


\section{Control object}

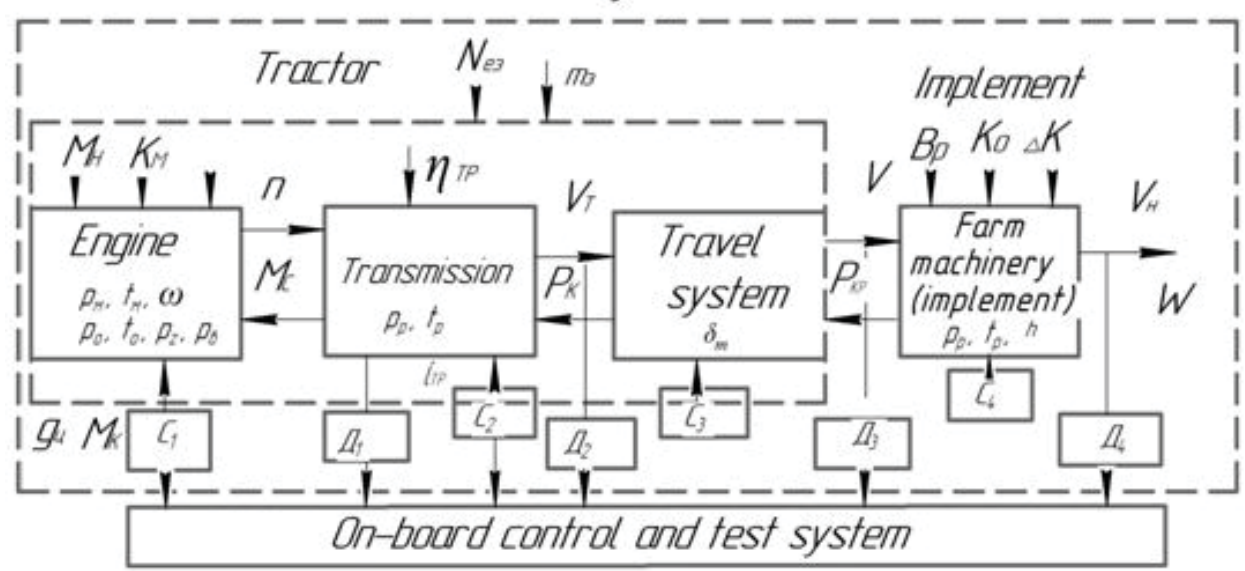

Figure 6: Structural scheme of management object "Tractor as an agricultural tool"

The tractor mechanical transmission transforms parameter $\omega$ into tractor theoretical velocity $V_{t}$ (drive wheels speed $\omega_{w}$ ), therefore the second group functioning at the input parameter - drive wheels tangential traction $P_{t}$, is estimated, using the following expressions:

$$
\left\{\begin{array}{c}
V_{m}=\pi * n * \frac{r_{\text {A }}}{30} * i_{m p} \\
P_{\mathrm{K}}=M_{C} * i_{T P} * \eta_{T} * / r_{d}
\end{array}\right.
$$

Where $i_{t r}$ - transmission gear ratio.

Interrelation of output $V_{m}$ and input $P_{K}$ parameters is defined based on the functional condition at $r_{d}=$ const, $i_{\text {TP }}=i d e m$

$$
V_{m}=\pi * n * M_{c} * \eta_{m p} / 30 * P_{\mathrm{K}}
$$

Transmission state and operation prediction can be assessed based on values $p_{p}, t_{p}$. We diagnosed the state of assembly part sand planned the repair based on these sensors readings together with the oil condition sensor, similar to the sensor, described below. Before the experiment we filled the engine lubricating system with motor oil $\mathrm{M} 10 \Gamma_{2}$, which resulted in the pressure reduction during the experiments from 7 to 4.5 bar at engine speed 2100 $\min ^{-1}$.

Pulling force Ркр and tractor rolling resistance $P_{f}=m_{g} \cdot g \cdot f$ were the external influences on the third experiment group. The output parameter is actual tractor velocity $V=V_{m} \cdot(1-\delta)$, which at the same time is the principal tractional aggregate parameter-marker. Its relationship with the input and set parameters is determined by the equations system:

$$
\left\{\begin{array}{c}
P_{K}=P_{K P}+P_{f} \\
V=\varepsilon_{N} \cdot N_{\mathrm{e}} \cdot \eta_{m p} \cdot(1-\delta) /\left(P_{K P}+P_{f}\right)
\end{array}\right.
$$

Parameters optimization criterion $\left(n, M_{\mathrm{k}}, i_{\mathrm{tr}}\right)$ for determination of energetic $(\mathrm{Ne})$ and pulling-adhesion tractor parameters $\left(\eta_{\mathrm{T} \text { max }}, \delta_{\mathrm{opt}}\right)$, known aggregate pulling force characteristics $\left(P_{\text {hook }}, \omega_{\text {phook }}\right)$ and operation speed values $\left(V_{H} \pm \Delta V\right)$ change intervals can be presented as a minimizing function.

$$
F=\left|\frac{\pi \cdot M_{\mathrm{e}} \cdot \omega_{H}}{30 \cdot N_{\mathrm{e}}}-1\right|+\left|\frac{\pi \cdot \omega_{H} \cdot \varepsilon_{N}}{30 \cdot V_{H} \cdot i_{K} \cdot \varepsilon_{M}}-1\right|+\left|\frac{P_{K P} \cdot m_{3} \cdot g \cdot f}{\eta_{\mathrm{Tp}} \cdot \varepsilon_{M} \cdot M_{H} \cdot i_{k}-1}\right| \rightarrow \min
$$

MTA operating efficiency with the set parameters of specific pulling force, in our case, was determined by net performance indicators $W\left(\mathrm{~m}^{2} / \mathrm{s}\right)$, specific energy consumption $E_{n}\left(\mathrm{~kJ} / \mathrm{m}^{2}\right)$ and per hectare fuel consumption $g_{w}(\mathrm{~kg} / \mathrm{he})$ :

$$
\left\{\begin{array}{c}
W=\varepsilon_{\mathrm{N}} \cdot \mathrm{N}_{\mathrm{e}} \cdot \eta_{\mathrm{m}} / \mathrm{K}_{\mathrm{o}}\left[1+\Delta \mathrm{K}\left(\mathrm{V}_{\mathrm{H}}^{2}-\mathrm{V}_{0}^{2}\right)\right] \rightarrow \mathbf{W}^{*} \\
\mathrm{E}_{\Pi}=\varepsilon_{\mathrm{N}}^{*} \cdot \frac{\mathrm{N}_{\mathrm{e}}}{W} \rightarrow \min , \\
\mathrm{g}_{\mathrm{W}}=\frac{2,77 \mathrm{G}_{\mathrm{m}}}{\mathbf{W}} \rightarrow \min .
\end{array}\right.
$$

If these parameters deviate from the limit values, the onboard continuous diagnostic system provides a control signal $\mathrm{Ci}$ to correct the system and transfer it to a stable state. In case of repeated unsatisfactory response, an error is indicated, which serves as the basis for making further decisions on the need for voice dialing, SMS, communication with the machine operator via an external microphone, including GPS, auto tracking, maintenance or repair.

The experiments revealed unreasonable fault alarms appearance. Therefore, the self-diagnostic algorithm and emergency operation mode were introduced in case of sensors breakdown. Actuators control output keys were equipped with short-circuit protection.

The diagnostic subsystem was implemented in the electronic control unit software, which allowed to determine current faults of the system and unit and record them. The errors received by the electronic unit during the experiments were transferred to the controller for processing and further transmitting to the service company diagnostic station (Figure 7). The remote diagnostic scheme was as follows:

1. To check operation of the on-board diagnostic system and diagnostic chain.

2. To determine the fault codes.

3. To transfer the faults, affecting MTA operation quality to the service center diagnostic station. 


\section{Diagnosis connector}

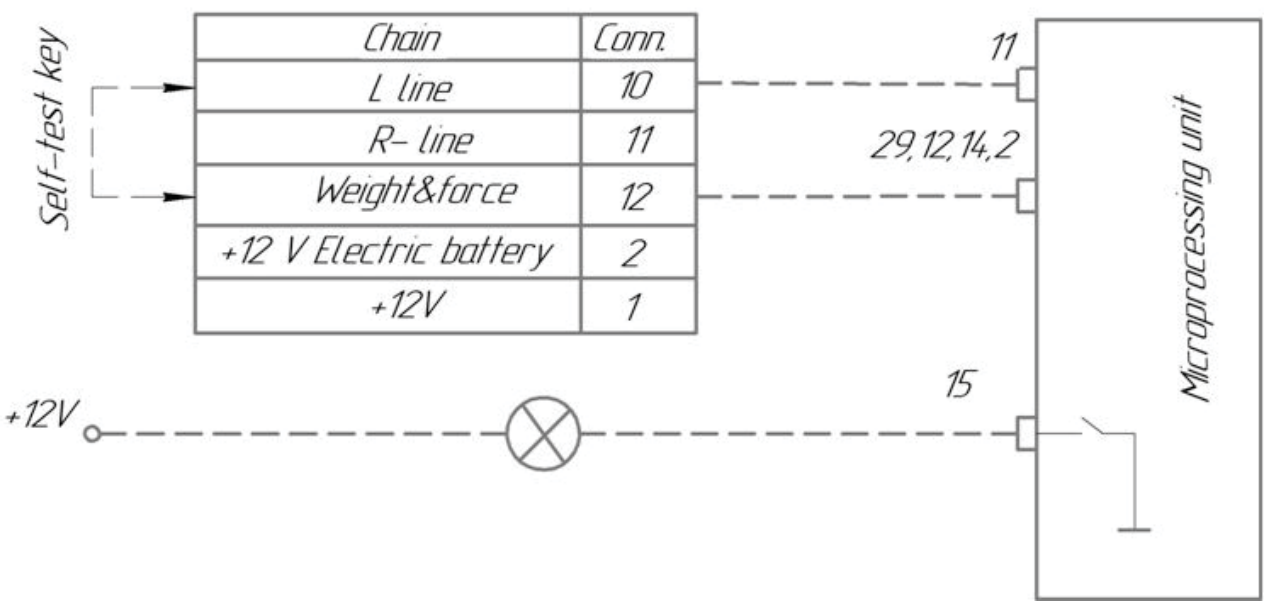

Figure 7: Scheme of the modified diagnostic chain

This study examined the sequencing of the vehicles in service through the diagnostic stations and technical maintenance. Such a system can be considered as a two-phase system with stand-by, which receives almost unlimited demands deluge. As long as different service departments can maintain various assemblies and aggregates, the principal simulation and optimization task is to receive such summary regularities and results, which can be applied to any vehicle type under any conditions.

In order to determine technical indicators of the two-phase diagnostic and technical maintenance system functioning we use the indicators of the number of traction vehicles, which are in the first phase (under diagnostic) $\mathrm{m}_{\mathrm{o} 1}$ and in the second phase (under technical maintenance) $\mathrm{m}_{\mathrm{o} 2}$, as well as the respective down-time probabilities of the men- tioned phases $P_{01}$ and $P_{02}$, depending on ratio $\alpha_{1}=\lambda / \mu_{1}$ and $\alpha_{2}=\lambda / \mu_{2}$ between demands density $\lambda$ and maintenance intervals $\mu_{1}$ and $\mu_{1}$ in each phase.

The summary dependency schedule in the diagnostic phase $m_{01}$ and technical maintenance phase $m_{02}$ respectively on $\alpha_{1}$ and $\alpha_{2}$ is shown in Figure 8. According to the schedule value $m_{01}$ is determined using dependence on $\alpha_{1}$ and $\mathrm{m}_{\mathrm{o} 2}$, using dependence on $\mathrm{a}_{2}$.

Values $\mathrm{m}_{\mathrm{o} 1}$ and $\mathrm{m}_{\mathrm{o} 2}$ with respective upturn $\alpha_{1}$ and $\alpha_{2}$ increase by hyperbolic dependence. Using acceptable values $m_{01}$ and $m_{02}$ and taking into account the production premises it is possible to determine respective values $\alpha_{10}$ and $\alpha_{20}$. Required maintenance intervals $\mu_{10}=\lambda_{0} / \alpha_{10}$ and $\mu_{20}=\lambda_{0} / \alpha_{20}$ can be determined using the set demands deluge $\lambda_{0}$.

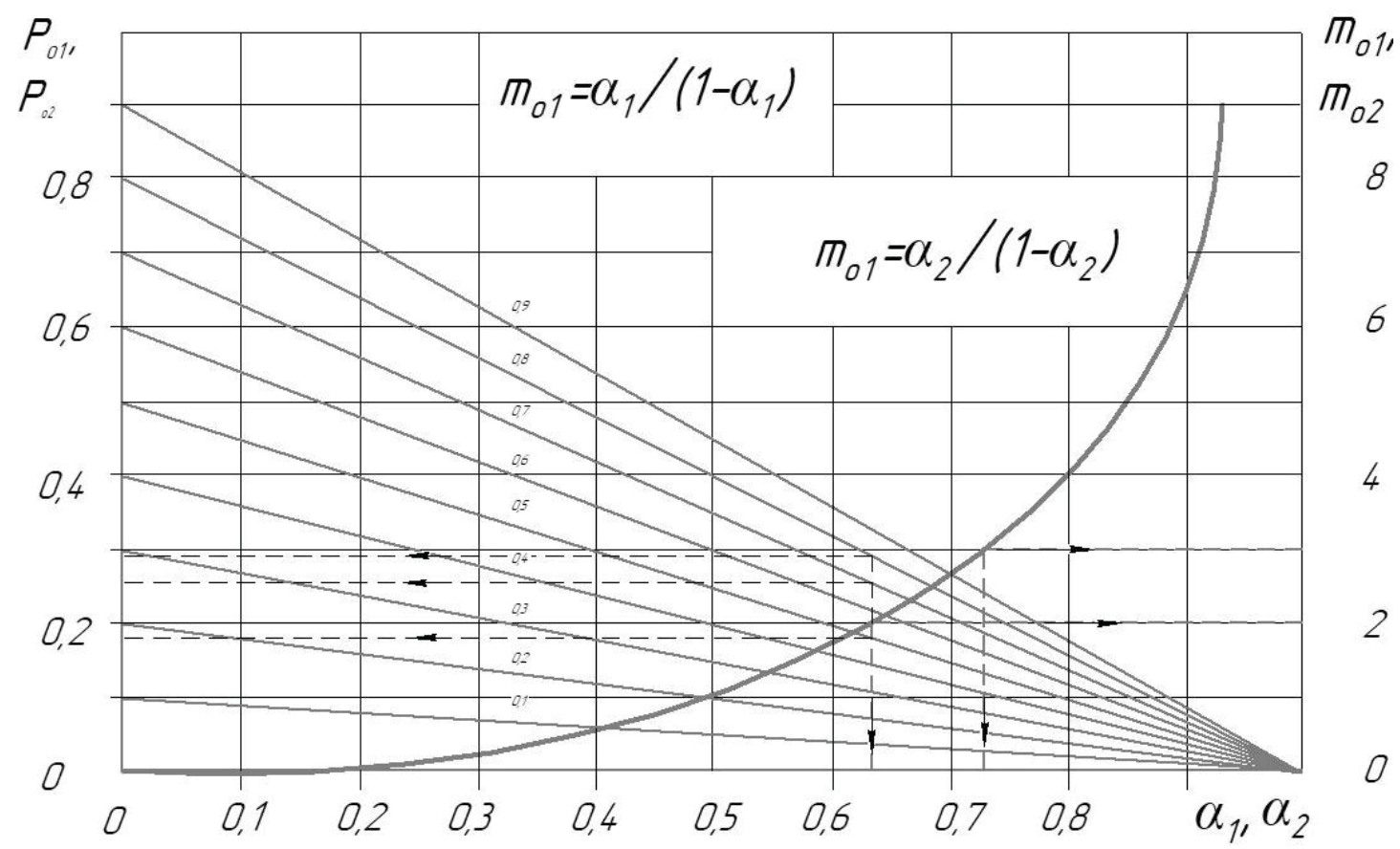

Figure 8: Summary dependency schedule in diagnostic phase mo1 and technical maintenance phase mo2 respectively on $\alpha_{1}$ and $\alpha_{2}$ 
For example, putting only two vehicles in each phase $\left(m_{01}=2, m_{02}=2\right)$, then, as it is shown in Figure 8, $\alpha_{10}=\alpha_{20}=0.63$. If demands density $\lambda_{0}=1.2$, required maintenance intervals $\mu_{10}=\mu_{20}=\lambda_{0} / \alpha_{10}=1.2 / 0.63=1.9$. Analogous solution can be made with different values $m_{01}$ and $\mathrm{m}_{\mathrm{o} 2}$. For example, if it is possible to put two vehicles in the first phase $\left(m_{01}=2\right)$, and three - in the second $\left(m_{o 2}=3\right)$, then $\alpha_{10}=0.63, \alpha_{20}=0.72$ in Figure 7 schedule. Herewith, maintenance intervals should be $\mu_{10}=1.9$ and $\mu_{20}=1.67$. The number of stations, diagnostic specialists and fixers can be determined using values $\mu_{10}$ and $\mu_{20}$.

Using known values $\alpha_{1}$ and $\alpha_{2}$ makes it possible to determine the respective probabilities of diagnostic station $P_{01}$ and technical maintenance $\mathrm{P}_{02}$. downtime (Figure 8). For example, in the first case at $\alpha_{10}=\alpha_{20}=0.65$, we get $P_{01}=$ $P_{02}=0.277$, as shown by arrows in Figure 8. At $\alpha_{10}=0.65$, $\alpha_{20}=0.72$ in order to determine $P_{01}$, value $\alpha_{10}$ is laid along the horizontal axis, and $\alpha_{10}$ - on the respective half ray. In this case we get $P_{01}=0.26$. Similarly, when determining Por, we lay value $\alpha_{20}=0.72$ according to the horizontal axis, and $\alpha_{10}=0.65$ - according to the half ray. In this case $P_{02}=0.188$ as shown by the dashed lines.

The system was equipped with the interface, specifying the aggregate location on the map, faults detection, operation time and required technical maintenance in order to facilitate identification and search(Figure 9).

The experimental study showed that the demand density for elimination of the technical faults can exceed possible number of the vehicles repaired in the service center (repair shop). By accepting the technical faults flow as distribution [6], it was determined that probability $P_{K}(T)$ of demands receipt $t$ for period $\mathrm{T}$ is computed using Poisson formula.

$\mathrm{P}_{\mathrm{K}}(\tau)=\left((\lambda \tau)^{\tau / \mathrm{t}}\right) \cdot \mathrm{e}^{-\lambda \tau}$

Many scientists proved with the experiments [1-5], that the faults flow of the tractors with adequate accuracy could be considered Poisson. Based on this we determine faults density $\lambda$ using equation $\lambda=1 / \tau_{\text {отк }}$

where $\mathrm{T}_{\text {OTK }}$ - average time between faults (time between faults), $1 / \mathrm{h}$.

It is supposed that servicing of each demand is performed by one stationary means, thus the interval of the respective maintenance is computed by equation

$$
\mu=1 / \tau_{0 \sigma}
$$

where $\mathrm{T}_{\mathrm{o}}$ - average duration of one fault elimination, $\mathrm{h}$.

Due to the increase in the duration of the fault elimination and in the failure density, a queue of waiting vehicles is formed. Thus, the flow should be reallocated to other services using a computer program.

The experiment showed that the use of the divided method, when reserving separate machines and aggregates elements, the downtime reduces to $19 \%$. It is possible to order reserving with whole or fractional multiplicity, depending on the quantitative ratio between the main and reserve elements or complete aggregates. If any reserve element or aggregate can replace the faulty principal, then it is considered a reserving with roving reservation. In this case, downtime reduces by another $5 \%$. During the experiments we offered to implement a probability of hot, light and cold reservation in the program.

This scheme implementation is an improved advanced analogue of the equipment technical maintenance (shown in red in Figure 10 for comparison) and current repair schedule preventive scheme.

When introducing the continuous diagnostic system (CDS) we used the feedback in order to adjust the engine operation in real time. It allowed us to monitor continuously the sensors readings and forecast in time the need for repair. Indirect indicators diagnostic (at temperature and exhaust gas composition, vibration during operation) allowed to widen the number of the diagnosed parameters, including for conditions determination of the mechanical compo-

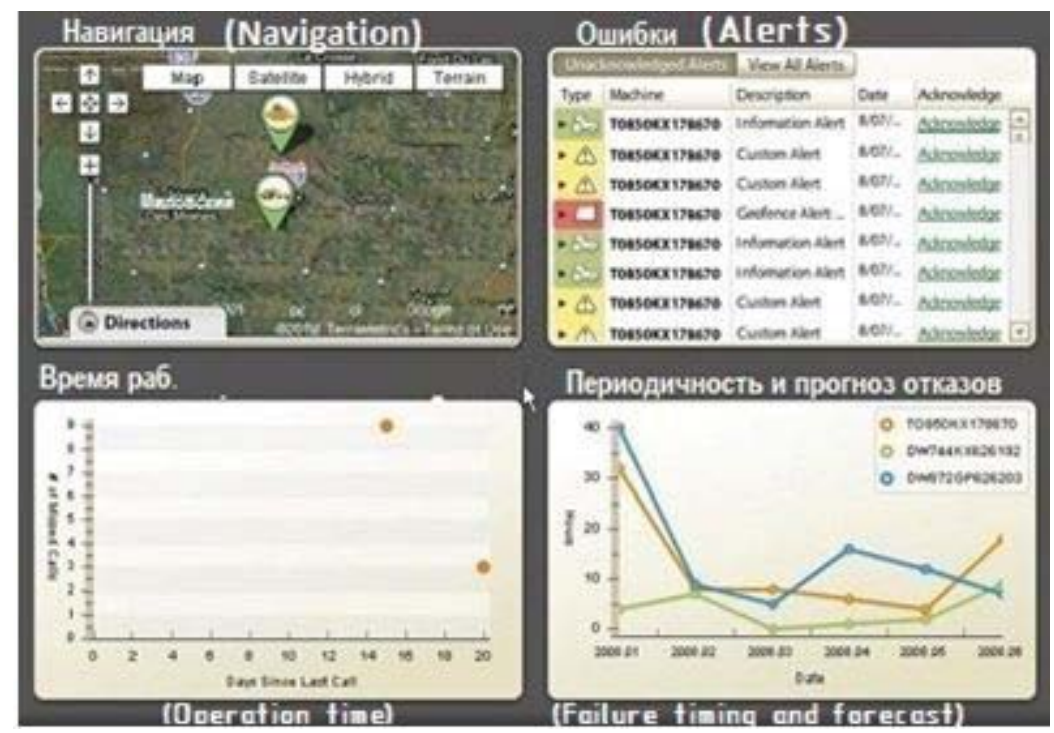

Figure 9: Software Interface Snapshot 
nents, cylinders, crank-shaft, fuel feeding and lubricating systems etc.

The repair warning works in the following way: the information is sent from the machine to the management subject model through GPS channel, and then it is stored and processed.

In case the repair is required, the management subject model makes a decision and informs the service company (SC) on the approximate date of equipment arrival for repair and its replacement, if necessary.

Usually, only a manufacturer or a dealer company have access to such works. Herewith, technical maintenance is a preventive measure, comprising a number of works, aimed at faults prevention, ensuring full operational capability of the vehicle aggregate, assembly or system. Tech- nical maintenance shall be performed in a planned manner through certain runs or a certain time of vehicle operation, avoiding downtime. When using a nominal scheme, a car or a tractor with broken aggregates, assemblies, systems and parts which can threaten traffic security, is not allowed to work an $d$ is idle. In this situation servicing is provided by the subject of management itself (a tractor-driver, figure 1 and 9) usually according to working hours.

The proposed system involves sending a message to the machine servicer phone before the shift starts, indicating only the required technical maintenance per shift and notifying autonomously the service company of the expected breakdown. The service company analysts shall make a final decision.

Statistical data processing was performed by regression

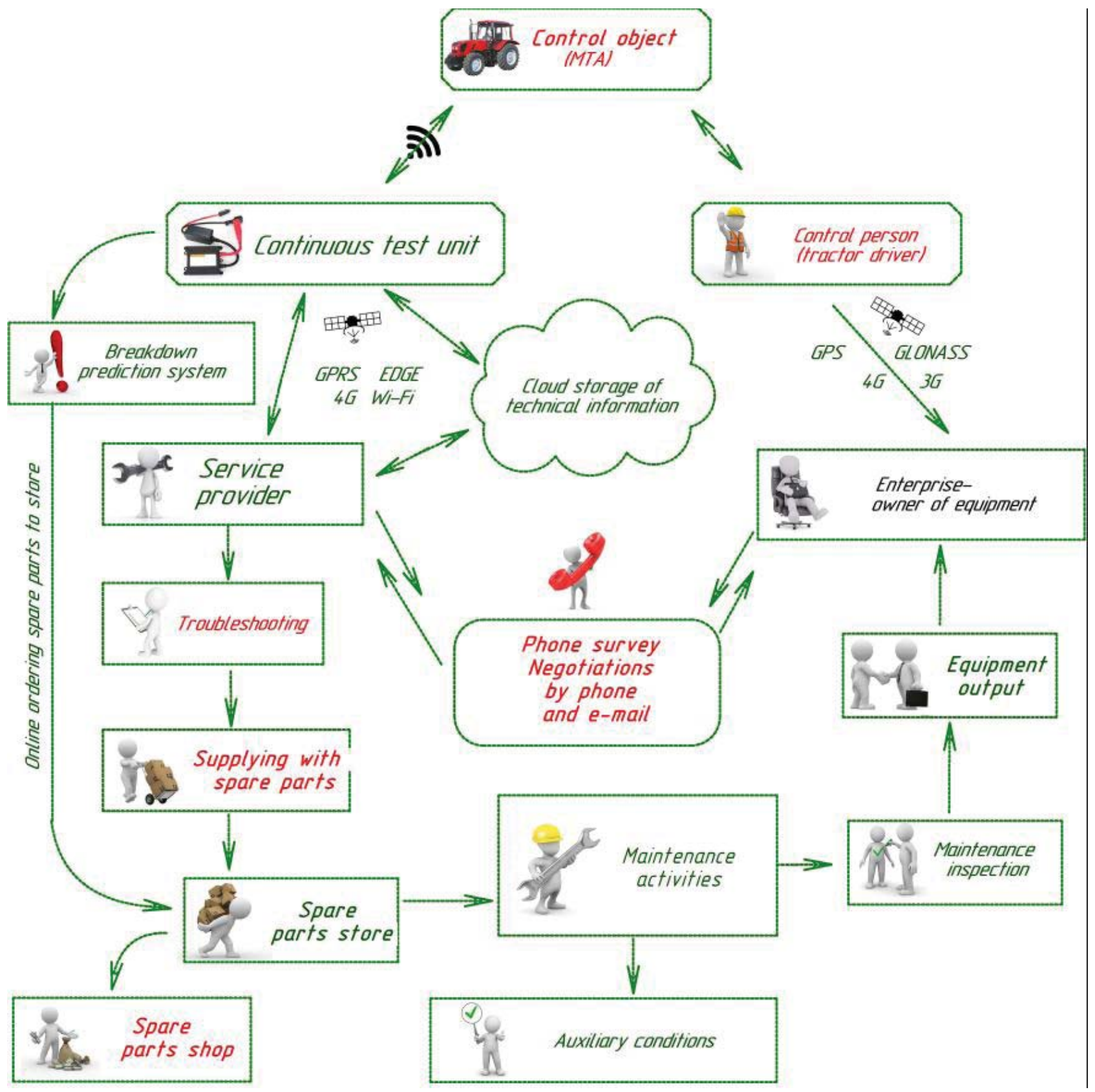

Figure 10: Continuous diagnostic system flow diagram MTA-CDS-SC 
analysis of functional dependencies. Mathematical analysis gave the following results for the formation of regression equations:

- $\quad$ multiple regression coefficient $R=0,9998971$;

- $\quad$ Fisher's criterion $\mathrm{F}=390,2639$;

Data evaluating criteria during remote monitoring are compared with cloud data that is slightly different from the builtin critical values, which are used by the customer's management system.

The data coming from a particular machine are compared with a huge database of the machinery of this class, which allows to use all the experience available to the system, and anticipating the tendency to deviate from a particular parameter, in a timely manner to exclude serious damage before it creates an emergency situation or an emergency equipment stopping.

The economic effect estimation due to the project proposals implementation was made on the difference of the total reduced costs for a comparable one-time scope of work. The economic effect due to the project proposals implementation was more than $5 \%$.

\section{CONCLUSIONS}

The structure of the technical state and fault prediction continuous diagnostic system for tractor and agricultural equipment include four groups of interrelated, speed, load and pulling-adhesive parameters-markers, ensuring effective tractor operation as part of MTA. The use of MTA systems remote diagnostic and self-diagnostic helps the management subject to speed up the diagnostic, narrowing the field of possible malfunctions and reduce down time. It is established that creation of a device for remote diagnosis of traction vehicle equipment by means of telecommunication means of GSM standard eliminates the waiting time for the vehicle servicing and provides a predetermined speed, load, thermal test mode in real operating conditions for performing quality diagnosis.

The program algorithm for workflow parameters measuring should compensate for the transformation errors based on the assumption that they are both systematic and random.

As for the repair shop we received summary optimal resource-saving combinations between demands density $\lambda$ and their maintenance interval $\mu$ over the entire possible range of their change $\lambda_{\text {oпт }}=0 \ldots 12$ and $\mu_{\text {oпा }}=0 \ldots 11$. Received values resource-saving parameters of the respective service systems under production. The practical application of the obtained general results of the study provides a significant increase in the efficiency of service stations specializing in machinery production and maintenance.

\section{REFERENCES}

1. Zangiev A.A., Didmanidze O.N., Mitiagin G.E. Higher operation efficiency of machine and tractor fleet repair shops. Moscow, Agroconsalt Publ., 2001. - 108 p.

2. Safin F.R., Insafuddinov S.Z., Gaisin E.M. Ways to test and adjust diesel fuel equipment and a stand for its implementation. Patentofinvention RUS 2562349 of 11.03.2014.

3. Selivanov N.I. Technological basics to adapt tractors. Krasnoiarsk, Publiching Company "Znak" Publ., 2017. 259 p.

4. Bosch Wilhelm. Der Einspritzgesetz-indikator, ein neues Meßgerat zur direkten Bestimmung des Einspritzgesetzes von Einzeleinspritzungen. Motortechn. - 1964. - №7. - VOL. 268-282.

5. Lachuga lu.F. and others.Strategy of machine and technological modernization of Russian agriculture for the period up to 2020. Moscow, Federal State Scientific Institution "Rosinformagrotekh" Publ., 2009. 80 p.

6. Poliak A.A. and others. Technical and economic criteria of the tractor mounting's limit state. Tractorsandfarmmachinery, 1981, No.2.

7. Chernoivanov V.I., Gabitov I.I., Negovora A.V. Digital technologies and electronic means in the system of cars, tractor and combines' maintenance and repair. // Proceedings of the International science to practice conference "Smart machine technologies and machinery in agriculture". Moscow, Russian Science Academy, Federal Scientific Farm Engineering center Publ., 2017.

8. Patent №3937087, G01L 9/04. Transducer for engine fuel injection monitoring.- Canadian Patents \& Development Limited, Canada. - Filed. 05.07.1974. Pub. 10.02.1976.

9. Ildar Gabitov, Samat Insafuddinov, Denis Kharisov, Filyus Safin, Andrei Negovora, Nail Yunusbaev, Alfir Akhmetov, Timur Farhutdinov and Albert Sharafeev, 2018. Diagnostics and Regulation of Fuel Equipment of Diesels on Stands with Injection to Medium with Counter-Pressure. Journal of Engineering and Applied Sciences, 13: 8782-8788. DOI: 10.3923/jeasci.2018.8782.8788. URL: http://medwelljournals.com/ abstract/?doi=jeasci.2018.8782.8788

10. Ildar Gabitov, Andrei Negovora, Eduard Khasanov, Rustam Galiullin, Mars Farhshatov, Rim Khamaletdinov, Vladimir Martynov, Dmitryi Gusev, Nail Yunusbaev and Mahmut Razyapov, 2019. Risk Reduction of Thermal Damages of Units in Machinery Heat Preparation for Load Acceptance. Journal of Engineering and Applied Sciences, 14: 709-716. DOI: 10.3923/ jeasci.2019.709.716 URL: http://medwelljournals.com/ abstract/?doi=jeasci.2019.709.716 
11. Ildar I. Gabitov, Gennadi P. Juxin, Vladimir M. Martynov, Rustam R. Galiullin, Konstantin V. Kostarev andrei V. Negovora, Salavat G. Mudarisov, Nail M. Yunusbaev, Arseny A. Kozeev and Denis F. Baltikov, 2018. Modeling the Power Plant Operation to Optimize the Technological and Design Parameters of the Gas Generator Unit. Journal of Engineering and Applied Sciences, 13: 8857-8864. DOI: 10.3923/jeasci.2018.8857.8864

12. Patent № 2429373 rus. Stand for testing and adjustment of diesel fuel equipment.- Bashirov R.M., Insafuddinov S.Z., Filed. 12.12.2011. Pub. 24.02.2012.

13. Segal, L. (1999). Diagnostic method for vehicle brakes. NDT \& E International, 32(7), 369-373.

14. Cavallo, E., Ferrari, E., \& Coccia, M. (2015). Likely technological trajectories in agricultural tractors by analysing innovative attitudes of farmers. Int. J. Technology, Policy and Management, 15(2), 158-177.

15. Raikwar, S., Wani, L. J., Kumar, S. A., \& Rao, M. S. (2019). Hardware-in-the-Loop test automation of embedded systems for agricultural tractors. Measurement, 133, 271-280.
16. Staszak, Ż., Selech, J., Marcinkiewicz, J., Romek, D., Włodarczyk, K.,Gierz, Ł., \& Wojcieszak, D. (2018). The diagnostic information valuation method in servicing tractors. In MATEC Web of Conferences (Vol. 182, p. 01013). EDP Sciences.

17. Mattetti, M., Molari, G., \& Vertua, A. (2015). New methodology for accelerating the four-post testing of tractors using wheel hub displacements. Biosystems Engineering, 129, 307-314.

18. Buklagin, D. S. (2016). DEVELOPMENT OF AGRICULTURAL MACHINERY TESTING TECHNOLOGIES. International Scientific Research Journal, No. 4 (46). Part 2, p. 45-51.

19. Sun, D., Chen, D., Wang, S., \& Wang, X. (2016). A dynamic instability detection and prediction system for high clearance tractor. IFAC-PapersOnLine, 49 (16), 50-54. 